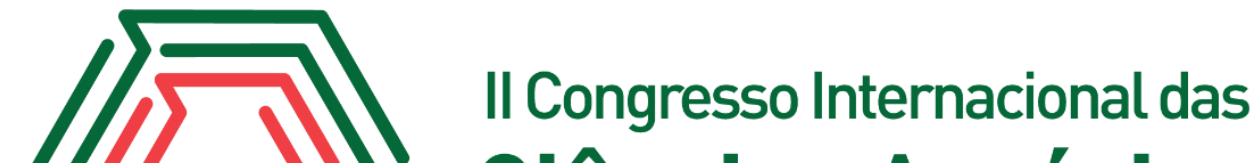 Ciências Agrárias COINTER - PDVAgro 2017
}

\section{PRODUÇÃO DE BIOMASSA EM PLANTAS JOVENS DE BACABA E BACABI SUBMETIDAS A ESTRESSE HÍDRICO E REIDRATAÇÃO}

Jessica Suellen Silva TEIXEIRA ${ }^{1}$; Milena Pantoja de MORAES ${ }^{2}$; Dielle Thaina de França TEIXEIRA ${ }^{3}$; Antônia Benedita da Silva BRONZE ${ }^{4}$; Cândido Ferreira de OLIVEIRA NETO ${ }^{5}$

\section{Introdução}

As palmeiras constituem-se numa das plantas mais utilizadas nas regiões tropicais, e entre as palmeiras nativas de valor socioeconômico para a Amazônia estão as do gênero Oenocarpus, sendo que segundo SILVA (2009) o principal interesse nas espécies Oenocarpus mapora Karsten (bacabi) e Oenocarpus distichus Mart. (bacaba) reside no aproveitamento de seus frutos para produção de óleo e de seu palmito, entre outros produtos derivados que possuem excelente qualidade nutricional.

Embora, essas espécies tenham grande importância alimentícia e econômica para região, elas ainda não foram domesticadas e os estudos de fisiologia de palmeiras são escassos, principalmente no que diz respeito aos mecanismos de tolerância a esta condição. Portanto, o objetivo dessa pesquisa foi avaliar a produção de biomassa em plantas jovens de Bacaba (Oenocarpus bacaba Mart.) e Bacabi (Oenocarpus mapora Karsten) submetidas a condições de plena irrigação, suspenção hídrica e reidratação.

\section{Fundamentação Teórica}

Segundo NOGUEIRA et al., (2001) entre os vários fatores limitantes da produção vegetal, o estresse hídrico ocupa posição de destaque, pois altera o metabolismo delas. De acordo com Jaleel et al. (2009) o estresse hídrico inibe o crescimento celular reduzindo o crescimento das plantas, afetando vários processos fisiológicos, como fotossíntese e respiração, bem como a produção.

\section{Metodologia}

O experimento foi realizado no período de março a julho de 2015, em casa de vegetação localizada na Universidade Federal Rural da Amazônia (UFRA), em Belém, sendo avaliadas duas

\footnotetext{
${ }^{1}$ Agronomia, Universidade Federal Rural da Amazônia, j.suellen_27@hotmial.com

2 Engenheira Agrônoma, milena.pantoja@hotmail.com;

${ }^{3}$ Agronomia, Universidade Federal Rural da Amazônia, dielletft@gmail.com

${ }^{4}$ Professora Doutora, Universidade Federal Rural da Amazônia, antonia.bronze@ufra.edu.br

${ }^{5}$ Professor Doutor, Universidade Federal Rural da Amazônia, candido.neto@ufra.edu.br
} 
espécies, constituídas de 40 mudas de Bacaba e 40 de bacabi, totalizando 80 mudas. O delineamento experimental utilizado para as duas espécies foi DIC em esquema fatorial (2x4) com dois regimes hídricos: irrigado (controle) e não irrigado (estresse), com 4 períodos de avaliações nos tempos $0,15,30$ e 35 (reidratação) e 5 repetições.

Foram mensuradas o CRA entre 4:00 e 5:00h da manhã, utilizando-se o método descrito por SLAVICK (1979); e de Biomassa: Massa Seca da Raiz (MSR); Massa Seca das Folhas (MSF), Massa Seca do Caule (MSC), Massa Seca da Parte Aérea (MSPA) e Massa Seca Total (MST). As análises estatísticas dos dados foram realizadas com o auxílio do programa SISVAR 5.4 e, as médias comparadas pelo teste de Tukey ao nível de 5\% de probabilidade.

\section{Resultados e Discussões}

Os resultados obtidos após 30 dias de experimentação mostram uma redução significativa no CRA das plantas de bacaba (Figura 1A) e bacabi (Figura 1B) submetidas ao déficit hídrico quando comparadas as plantas controle. No que se refere ao período de 5 dias de reidratação das plantas, de acordo com Chaves, Maroco e Pereira (2003) para as plantas recuperarem completamente os níveis de fotossíntese na folha elas devem apresentar um CRA superior a 60-70 $\%$, sendo que a reidratação contribuiu apenas para que as plantas de bacaba se restabelececem da deficiência hídrica (Figura 1A), uma vez que passaram a ter um CRA de 84,32 \%. Enquanto que nas de bacabi houve redução do CRA.

Figura 1. Valores de CRA obtidos nas plantas de bacaba (A) e bacabi (B) submetidas aos tratamentos controle e deficiência hídrica, seguido de um período de reidratação. Fonte: Própria.

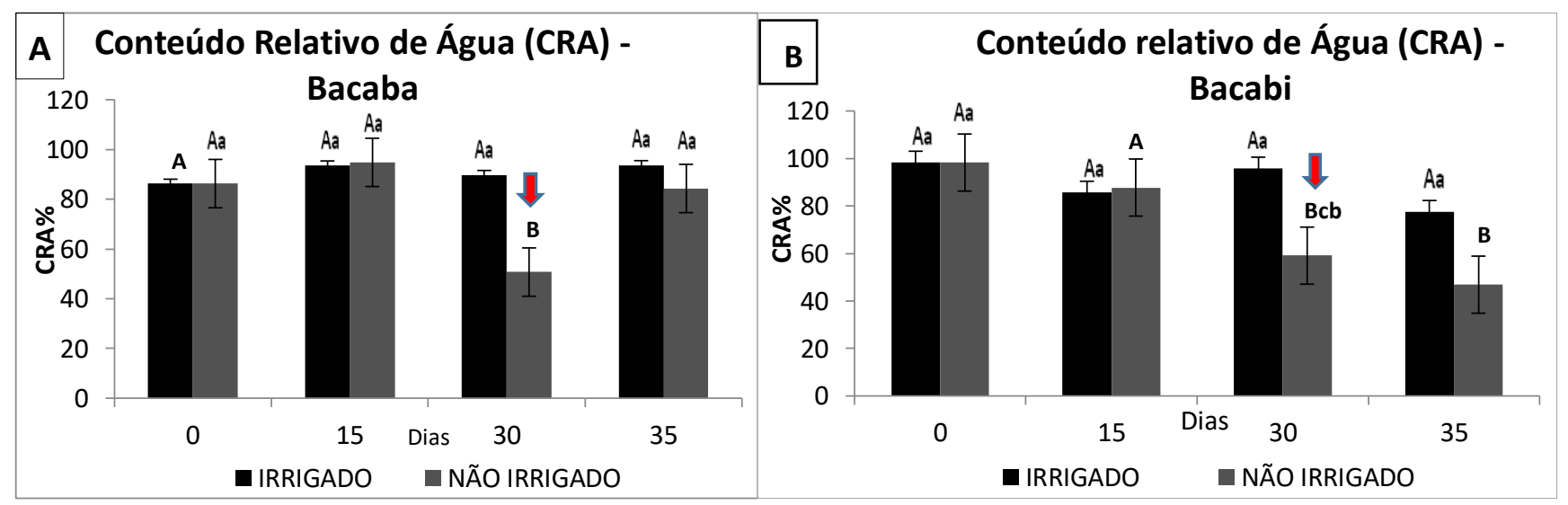

Letras diferentes mostram diferenças estatísticas comparadas pelo teste de Tukey ao nível de 5\% de probabilidade. As barras representam o erro padrão das médias. A seta vermelha indica o início do período de reidratação das plantas.

As produções de massa seca nas folhas (MSF) das plantas de bacaba (Figura 2 A) e bacabi

(Figura 2B) no tratamento controle tiveram um aumento, sendo os maiores acúmulos registrados aos 35 dias de experimento. Esse acúmulo é reflexo do crescimento e desenvolvimento dessas plantas, que dispõem de condições necessários para o bom desenvolvimento dos vegetais. 
Figura 2: Massa Seca da Folha (MSF) das plantas jovens de bacaba (A) e de bacabi (B) submetidas a duas condições hídricas distintas, irrigado e não irrigado, em quatro períodos. Fonte: Própria.

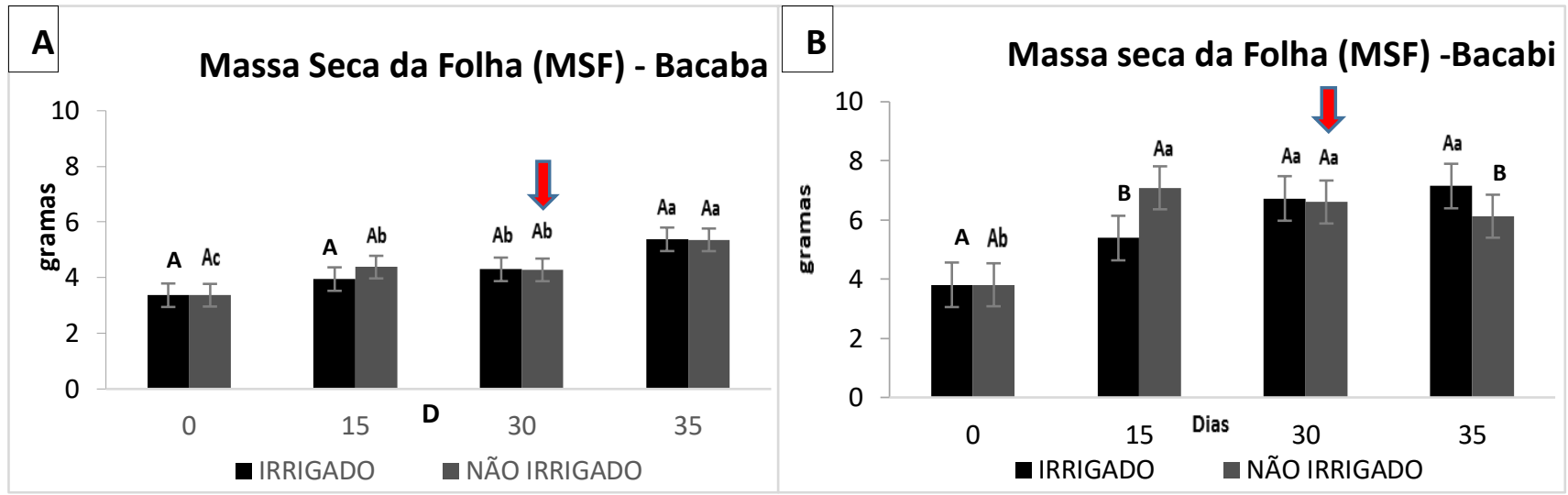

Médias seguidas da mesma letra não diferem estatisticamente entre si pelo teste de Tukey a 5\% de probabilidade. Letras maiúsculas comparam os valores entre as condições hídricas e as letras minúsculas entre os períodos de avaliação. As barras representam o erro padrão das médias. A seta vermelha indica o início do período de reidratação das plantas.

A condição de deficiência hídrica na massa seca do caule (MSC) não variou muito na bacaba, enquanto no bacabi houve variação durante os 30 dias de déficit hídrico. Essa diferença entre as duas espécies, mostra grande variabilidade genética das plantas avaliadas. Larcher, (2004) relata que os efeitos da seca sobre os vegetais dependem da intensidade do estresse, da genética da planta e da duração podendo provocar diversas alterações ecofisiológicas na planta. No que referese à reidratação, as duas espécies mostraram uma queda na sua biomassa.

Figura 3: MSC das plantas de bacaba (A) e bacabi (B) submetidas a duas condições hídricas distintas. Fonte: Própria.

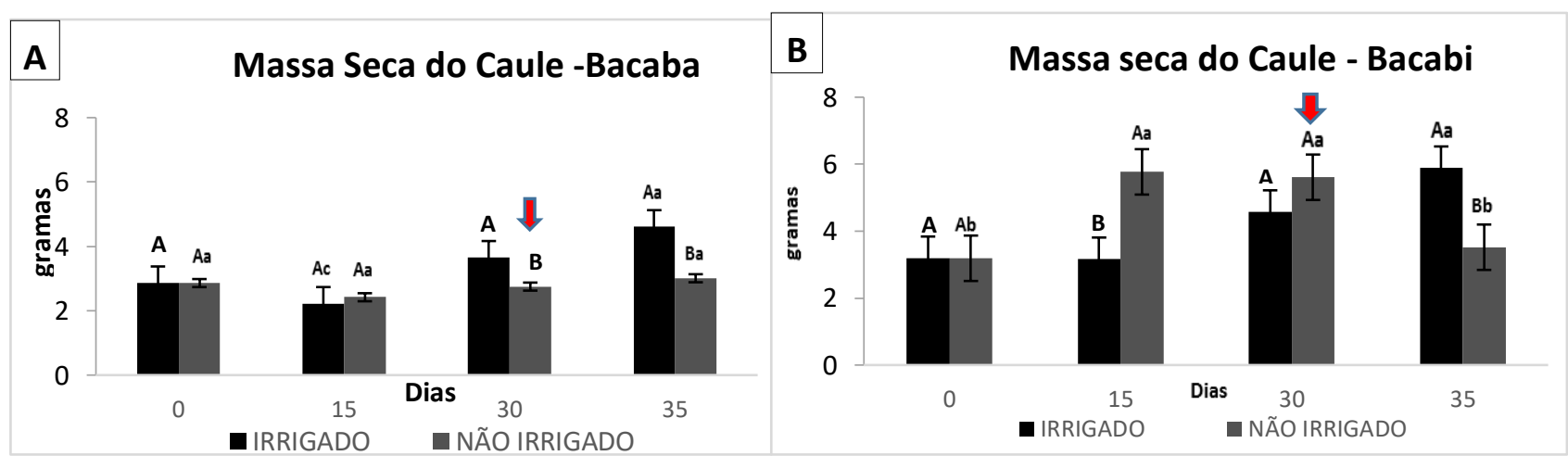

Médias seguidas da mesma letra não diferem estatisticamente entre si pelo teste de Tukey a 5\% de probabilidade. Letras maiúsculas comparam os valores entre as condições hídricas e as letras minúsculas entre os períodos de avaliação. As barras representam o erro padrão das médias. A seta vermelha indica o início do período de reidratação das plantas.

O volume de massa seca da parte aérea (MSPA) das mudas de bacaba (Figura 4A) e bacabi (Figura 4B) aumentaram ao logo do experimento tanto nas plantas controle quanto nas sob estresse. A condição de déficit hídrico no tecido das plantas causaram um aumento na produção de biomassa na parte aérea das duas espécies, atingindo seus maiores valores a partir do $15^{\circ}$ dia (do déficit hídrico). Esse aumento nos valores de massa seca da parte aérea, indica uma possível fragilidade da 
planta ao déficit hídrico. A reidratação aumentou em 1,33 \% a massa da bacaba e diminuiu em 2,56 $\%$ as de bacabi.

Figura 4: Massa Seca da Parte aérea (MSPA) das plantas de Bacaba (A) e Bacabi (B). Fonte: Própria.

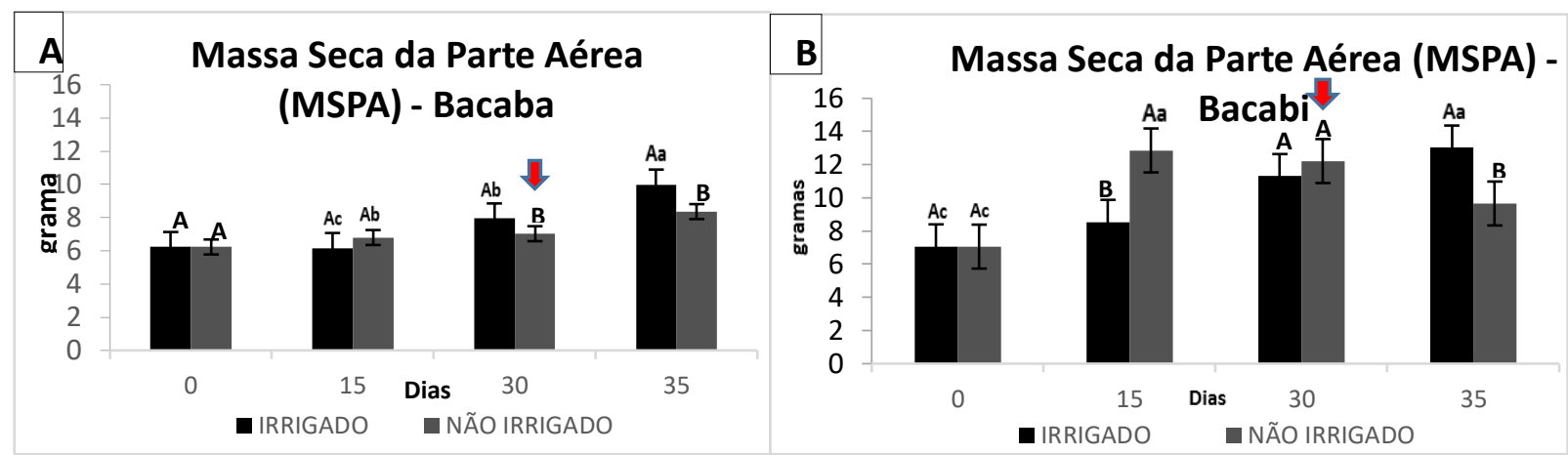

Médias seguidas da mesma letra não diferem estatisticamente entre si pelo teste de Tukey a 5\% de probabilidade. Letras maiúsculas comparam os valores entre as condições hídricas e as letras minúsculas entre os períodos de avaliação. As barras representam o erro padrão das médias. A seta vermelha indica o início do período de reidratação das plantas.

As produções de massa seca das raízes (MSR) das plantas jovens de bacaba (Figura 5A) e bacabi (Figura 5B) no tratamento irrigado obtiveram um aumento ao logo do experimento. Esse comportamento é considerado normal, uma vez que para as plantas controle, o ambiente de crescimento e desenvolvimento é propício. A deficiência de água causou um aumento na massa seca acumulada nas raízes das duas espécies, mas, esse comportamento foi mais significativo após 15 dias de experimento. A reidratação causou uma redução nessa produção de massa seca das referidas espécies. Representando assim, uma tentativa de contornar a seca por meio do acréscimo da área de absorção no solo (NOGUEIRA et al. , 2001).

Figura 14: Produção de MSR das plantas de Bacaba (A) e bacabi (B) submetidas a estresse hídrico. Fonte: Própria.

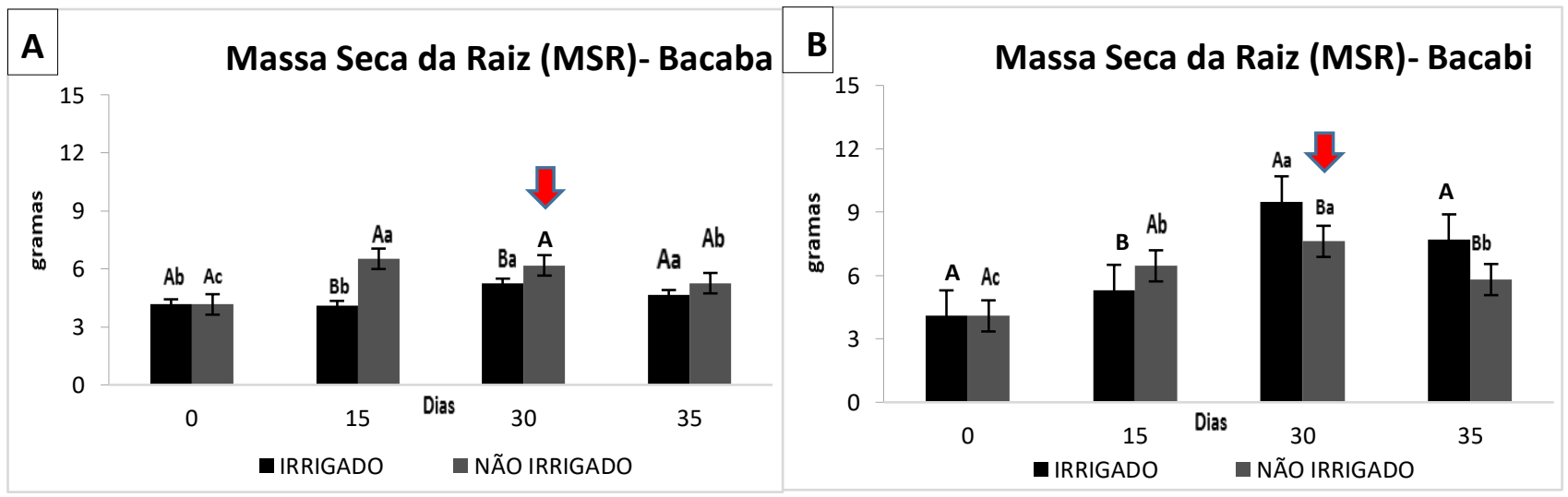

Letras maiúsculas comparam os valores entre as condições hídricas e as letras minúsculas entre os períodos de avaliação. As barras representam o erro padrão das médias. A seta vermelha indica o início do período de reidratação das plantas.

O déficit hídrico causado pelos 30 dias de suspensão de irrigação afetou significativamente o volume de massa seca total (MST) acumulada nas plantas das duas espécies ao longo do experimento (Figura 6A,B). As plantas controles apresentaram aumento da MST. As plantas de 
bacaba e bacabi submetidas à suspensão hídrica apresentaram um aumento significativo ao $30^{\circ}$ dia de experimento e na reidratação foi observada uma pequena redução.

Figura 6: Dados da produção de Massa Seca Total das plantas de bacaba (A) e bacabi (B), submetidas a dois tratamentos hídricos distintos, Irrigado e não irrigado.

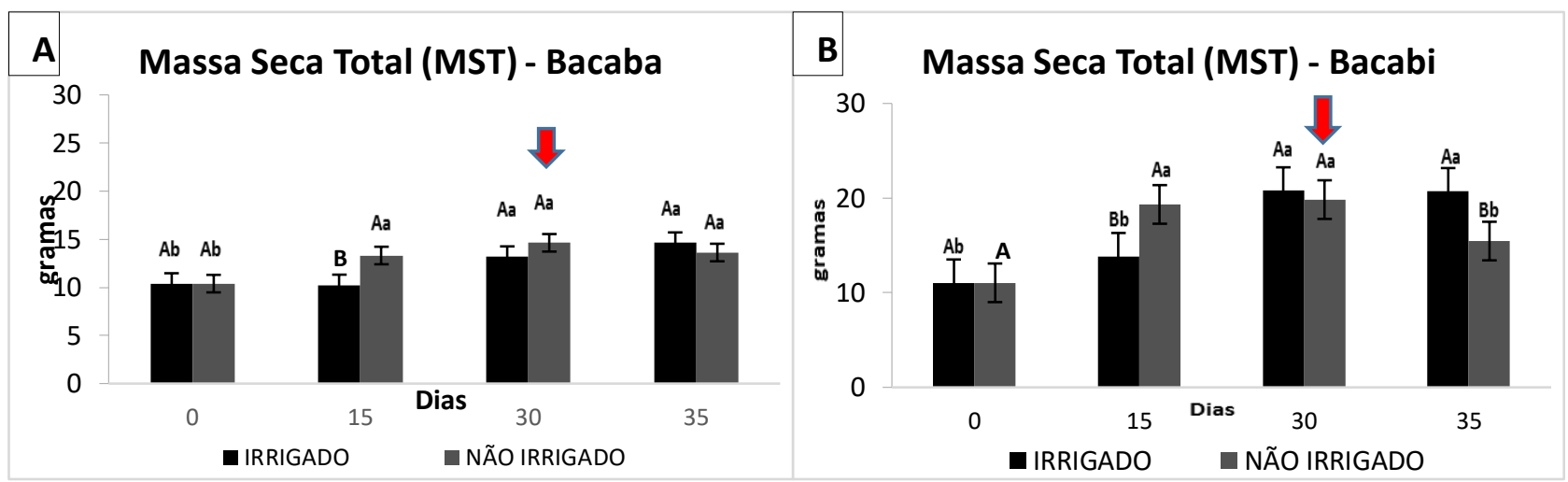

Médias seguidas da mesma letra não diferem estatisticamente entre si pelo teste de Tukey a 5\% de probabilidade. Letras maiúsculas comparam os valores entre as condições hídricas e as letras minúsculas entre os períodos de avaliação. As barras representam o erro padrão das médias. A seta vermelha indica o início do período de reidratação das plantas.

\section{Conclusões}

As condições hídricas influenciaram diretamente o metabolismo das espécies, e estimularam estratégias de resistência ao déficit hídrico, principalmente para as plantas da espécie $O$. bacaba Mart. que conseguiram se reestabelecer do estresse hídrico após cinco dias de reidratação.

\section{Referências}

CHAVES, M.M.; MAROCO, J.P.; PEREIRA, J.P. Understanding plant responses to drought - from genes to the whole plant. Functional Plant Biology, v. 30, p.239 - 264. 2003.

JALEEL, C. A., MANIVANNAN, P., WAHID, A., FAROOQ, M., AL-JUBURI, H. J. SOMASUNDARAM, R., PANNEERSELVAM, R., 2009. Drought Stress in Plants: A Review on Morphological Characteristics and Pigments Composition. International Journal Agricultural Biology, v. 11, p. 100-105.

LARCHER, W. Ecofisiologia Vegetal. Tradução: Prado, C. H. B. A. São Carlos: Rima, 531 p. 2006.

NOGUEIRA, R.M.C., MORAES, J.A.P.V., HÉLIO ALMEIDA BURITY, H.A., BEZERRANETO, E. Alterações na Resistência à Difusão de Vapor das Folhas e Relações Hídricas em Aceroleiras Submetidas a estresse de Água. Revista Brasileira de Fisiologia Vegetal, 13:(1), 7587, 2001.

SILVA, R. J. F. Anatomia foliar comparada em espécies de OenocarpusMart. (Arecaceae) de Belém, Pará, Brasil: uma contribuição taxonômica. 2006. 91 f. Dissertação (Mestrado em Botânica) - Universidade Federal Rural da Amazônia, Belém, PA.

SLAVICK, B. Methods of Studying Plant Water Relations. Springer-Verlag, New York. 1979. 